\title{
Role of Swiss Entrepreneurship Ecosystem
}

\section{4}

\section{Why This Chapter?}

This chapter will strike the reader as being quite different than the previous chapters and analyses. This is deliberate and placed toward the end of the book in order to provide some additional perspective to the previous analysis. Describing the background of the founders and entrepreneurs behind the 36 researched companies, pulling together details about the practices that brought these companies to market leadership in their chosen segments, and putting the spotlight on the respective governance practices risked missing an important point: To what extent were these entrepreneurial practices freely chosen by individual entrepreneurs and to what extent were they influenced by the Swiss entrepreneurship ecosystem?

Since this question accompanied much of the research and was also indirectly aired in the company interviews, we felt it necessary to also highlight this issue separately. While the answer cannot possibly be completed in the space of a single chapter, the thoughts of keen observers of the Swiss way of running enterprises, and an economy as a whole, should be of interest to those close to this environment, as well as interested readers from abroad.

Sources for this chapter include a number of writings from social scientists in a variety of fields, ranging from political science and economics, to history. Most of these authors have commented specifically on which factors have influenced the Swiss economic system over time, as well as compared the Swiss situation to that in other countries. These sources contribute to a better understanding of the entrepreneurial practices researched for this book, outlining how they are rooted in the historic and social background of Switzerland and did not emerge in a vacuum. Still, the authors strongly believe that these practices might also be applicable in other countries, with some adaptations to accommodate the respective institutional and cultural contexts. This idea will be visited later in the chapter. 


\section{Why So Many SMEs in Switzerland?}

In 2018, Narayama Murti, cofounder of Infosys, a leading Indian IT company, met local business representatives and government officials in Zurich where he was briefed on the large number of successful Swiss SMEs exporting all over the world. ${ }^{1}$ During the ensuing open conversation, he asked why Switzerland was the host to so many of these firms, something that did not exist in India. A lively conversation developed around this issue and continued to linger in the minds of those present, including one of the authors, who eventually became part of the conversation surrounding this research project.

Although involved with the practices of Swiss SMEs for many years, the authors continued to question the origin of these companies and the role the Swiss ecosystem. It became part of the conversation within the research team, and therefore, the determination was made that this issue needed somehow to be addressed. Is this situation unique to Switzerland? Is this about Swiss exceptionalism? Could Switzerland serve as a role model for other countries? Is the fact that these companies continue to prosper a function of the social and legal environment, or, to what extent are the practices documented in this book simply good management, adopted independently of the environment?

Meeting the Indian entrepreneur demonstrated that a more coherent, articulated, and fact-based answer was needed. This triggered a research effort that was to lead into the fields of history, literature, and political science, while reviewing the contributions of a diverse number of thinkers, stretching over more than 200 years. Over the next few pages, the findings from this journey will be reported.

\section{Swiss Tradition of Entrepreneurship}

For many years, the Global Entrepreneurship Monitor (GEM) tracked the prevalence and intensity of entrepreneurial activity in a number of countries, publishing an annual report. ${ }^{2}$ In 2019, GEM pioneered the National Entrepreneurship Context Index (NECI) to measure ease of starting and developing a business in a given country. Among the more than 50 countries ranked, Switzerland topped this list. ${ }^{3}$

Although these data are of recent origin, they nevertheless can be taken as an indication that Switzerland provided excellent framework conditions for entrepreneurship activities in the past, as well as in the current time. The entrepreneurship endeavors covered by the GEM survey went beyond the narrower focus of this

\footnotetext{
${ }^{1}$ Narayama Murti, Cofounder Infosys, Asia Leaders Series, Zurich, November 20, 2018.

${ }^{2}$ Reynolds P, Bosma N, Autio E, Hunt S, De Bono N, Servais I, Lopez-Garcia P, Chin N (1998-2003) Global entrepreneurship monitor: data collection design and implementation. Small Business Economics 24(3): 205-231.

${ }^{3}$ GEM Report. Switzerland: the top-ranked country for ease of starting and developing a business. Global press release, GEM website, https://www.gemconsortium.org. Accessed May 26, 2020.
} 
project, including services companies, domestically oriented businesses and agricultural companies-all outside the focus of this present study. Thus, the specific interest here is in finding the underlying factors that contributed to the high performance based on the described practices at the heart of this large concentration of exporting manufacturing companies.

Based on the company interviews, as well as the literature review, several supporting factors that contribute to the prevalence of exporting, manufacturingbased SMEs could be identified.

- Tradition for practical orientation among the Swiss population: techne versus episteme.

- Dual-track educational system with a strong vocational tradition.

- Engineering culture with a knack for ingenuity and innovation.

- Cooperative governance practiced across many levels of Swiss society.

- Deeply rooted work ethic.

- Distinct business management philosophy different from the Anglo-Saxon type.

In the following sections, each of these elements listed above will be examined further.

\section{Techne vs. Episteme: A Wall Street Banker's Observation}

Most readers are probably familiar with the writings of Nassim Nicholas Taleb of Black Swan ${ }^{4}$ fame and author of a later book entitled Anti-Fragile. ${ }^{5}$ Taleb spent some time working in Zurich in his early banking and investment advising career. From that experience, he observed that Switzerland, despite its success (he calls it arguably the most successful country in history), had traditionally produced a low number of university graduates compared to other highly developed nations.

Taleb observed that, even in banking, the Swiss apprenticeship model with its emphasis on vocational education departed from other financial centers, which tend to rely on university-based, theoretical training. This prompted Taleb to describe a particular balance achieved and maintained between techne, ${ }^{6}$ a preference for crafts and representing know-how, and episteme, ${ }^{7}$ standing for learned knowledge or know-what, that he viewed unique to the Swiss educational system and one that has been prevalent throughout Swiss industry.

Earlier visitors to Switzerland had noticed the same orientation. André Siegfried (1875-1959), a renowned French geographer and political scientist, as well as member of the Académie Française, traveled through Switzerland shortly after

\footnotetext{
${ }^{4}$ Taleb, N (2008) The black swan. Penguin Books, London.

${ }^{5}$ Taleb, N (2012) Anti-Fragile. Things that gain from disorder. Penguin Books, London.

${ }^{6}$ Techne, a term derived from Greek and meaning craftsmanship or art. Ibid, p. 90.

${ }^{7}$ Episteme, a term derived from Greek, to indicate knowledge. Ibid.
} 
WWII, recording his impressions of people, industry, and the country's political system. "Swiss industry is the daughter of a magnificent double tradition, artisan and scientific; the one born in the uplands of the ingenuity of the peasants, the other born of the splendid civilization of Switzerland's towns since the Middle Ages. Together, they formed a basis on which the Swiss qualities of industry and intelligence coupled with an advanced technique could develop in full."

Jean-Pierre Etter, founder of LEM, one of the companies profiled in this book, pointed out the importance of not confusing knowledge with know-how. Losing the ability to differentiate between those two forms of knowledge could lead to recording masses of unverified information while at the same time lessening a capacity to do something real. "To verify one's knowledge in industry is to be capable of applying in practice what one has learned in theory. Thought should not be based on abstract knowledge but reflect reality. Man thus achieves true knowledge of reality. Today, people no longer submit to this discipline and this is why belief or pure knowledge prevails over know-how.",

Etter considered this to be a dangerous development and thus strongly favored know-how over knowledge or know-what. Clearly, there is a long-standing tradition in Swiss society that appreciates the difference and favors know-how, or skills, over only the know-what.

\section{Swiss Dual Education System}

At the heart of the Swiss emphasis on skills and know-how was the country's dualtrack educational system. Compared to other European countries, the Swiss educational system produced a remarkably low percentage of university graduates in relation to the working population. This was even more astounding since a highly technically oriented industry required a workforce with top qualifications. With only about 20 percent of young Swiss graduating with a maturity, ${ }^{10} 30$ percent, if one includes the related program combined with an apprenticeship, Switzerland lags considerably behind other countries such as Finland, Sweden, Italy, or the EU on average (63 percent). ${ }^{11}$ Even Germany, another country that has a dual educational system, exceeds the percentage of Switzerland, considerably.

Complementing the aforementioned academic pathway, the Swiss system of apprenticeships was the backbone of skilled workers' training and actively supported by industry, as was pointed out in our analysis of Swiss SMEs. These programs, typically of three or four years in duration, graduated highly skilled professionals in many different job classifications annually, particularly in

\footnotetext{
${ }^{8}$ Siegfried, A (1950) Switzerland: A democratic way of life. Jonathan Cape, London.

${ }^{9}$ Etter, JP (1994) Start small, grow big, stay human and conquer the world. Editions Slatkine, Geneva.

${ }^{10}$ The Swiss Maturity is the qualification that leads to entry into universities.

${ }^{11}$ Strahm, RH (2014) Die Akademisierungsfalle. HEP Verlag, Bern.
} 
manufacturing-related industries. Swiss apprentices regularly competed in the international Olympics for apprentices where they consistently won medals. For example, at the 2017 World Skills Competition in Abu Dhabi, Switzerland as a nation came in second only behind China; Korea was ranked third. Switzerland's 36 participants earned 33 medals and recognitions (11 Gold, 6 Silver, 3 Bronze, and 13 Medals of Excellence), many of those in metalworking occupations. ${ }^{12}$

A former CEO of one of our interviewed companies provided this vignette, illustrating the strength of technical skills on the machine shop floor of one of these companies. "My company at that time acquired a new and sophisticated machining center from a German supplier. The company arrived with the equipment, installed it and turned it over to us. The supplier left us with three keys: 'Blue is for top management of your company and controls all of the parameters of the equipment; Red is for your technical and engineering staff to arrange for the machine set-up and programming; Green is for equipment operators on the shop floor and will turn the equipment on and off'. The machine supplier was puzzled when I told him 'Everyone here in this company gets a blue key'!"13

This is just one example of the technical skills present from bottom to top, feeding the companies with the necessary talent to compete globally.

Completing an apprenticeship program does not mean that the person remains at the skilled operator level for the rest of his or her professional career. As was pointed out in Chapter 2, many of the founders of the researched SMEs were graduates of apprenticeship programs who later completed additional education, mostly in management. This was not only the case for companies started decades ago, but it also applied to firms founded more recently (Wyon, Medartis) and many of the firms owned and managed today (Sylvac).

To perpetuate and support the dual education system, virtually all companies interviewed were active participants in the apprenticeship system, the numbers of apprentices in training ranging from a few to as many as 50 or more (Komax, maxon, Pilatus), depending on the size of the workforce.

"We at maxon train currently about 50 apprentices. We would like to double that. To achieve this, we will have to recruit more regionally for our program and possibly even offer dormitory-style housing."14

\section{A Knack for Engineering Ingenuity}

A perceptive analysis of the practical orientation of Swiss science was rendered by Denis de Rougemont (1906-1985), the renowned Swiss writer and political scientist, describing some of the Swiss scientists who made important contributions in the

\footnotetext{
${ }^{12}$ World Skills 2017 in Abu Dhabi, Medal Count by Country. https://worldskills.org/what/ competitions/wsc2017/.

${ }^{13}$ Example provided by Beat Kaufmann, former CEO of DC Swiss.

${ }^{14}$ Interview with Eugen Elmiger, CEO, maxon, January 22, 2019.
} 
eighteenth Century. Contrasting the Swiss approach to engineering with the one practiced in the USA, Rougemont pointed out that Swiss engineers, partly due to a lack of natural resources, could not compete with, and would not develop, the largest of anything, or engage in mass-produced products. Instead, the Swiss engineering approach was to create, for instance, the smallest watch, not the biggest one.

"Combining a taste for beauty and form in their work with a traditional appreciation for precision in manual labor, the Swiss felt compelled to add a new factor to their competitiveness leading to a novel approach to compensate for their handicap in market size: technical ingenuity and inventiveness, relying on a particular scientific tradition." 15

Rougemont cited the experience of the Basel mathematician Leonard Euler ${ }^{16}$ who found himself in need of proving the practical applications of his mathematical research, such as the creation of the differential and integrational calculus, by following up with a plan how to build turbines. Likewise, the Bernoulli family also expanded their mathematical knowledge developing the fundamental laws of mechanical engineering. To this day, industry worked on the basis of these mathematical models and, applied to statistics, these models found their way into the insurance industry. ${ }^{17}$

Siegfried, contrasting the Swiss approach to the mass approach practiced in other countries, describes Swiss industry as follows:

"They concentrate on specialization, on quality, on diversifying models rather than simplify them, in short, they 'build to a specification'. They are prepared to make innumerable adjustments, corrections and alterations; they prefer a reduced series, or even a succession of different products each treated as a thing in itself, to automatic production in series involving a rigid tooling-up; with that policy they accept the necessity of long and patient effort involving extended research and continued adaptation." 18

The engineering orientation of many of the company founders in this book was evident from glancing at their backgrounds, and the same applied to checking up on the professional backgrounds of the managers leading many of these firms today. The major educational institutions at the forefront of educating these talents were the Federal Institute of Technology in Zurich (ETH) and its sister institution in Lausanne (EPFL), as well as a number of engineering departments, which are now part of the University of Applied Sciences system. The ETH Zurich followed a long tradition for merging science with practical applications. With 32 Nobel Prize Laureates associated with ETH Zurich, the institution was ranked sixth worldwide by the QS

\footnotetext{
${ }^{15}$ de Rougemont, D (1970) La Suisse ou l'histoire d'un people heureux. Le Livre du Mois, Lausanne. Translated from French by the authors.

${ }^{16}$ Leonard Euler (1707-1783).

${ }^{17}$ The Basel Bernoulli family produced a number of outstanding mathematicians including Jacob Bernoulli (1655-1705, calculus), Johann Bernoulli (1667-1748, calculus), Daniel Bernoulli (1700-1782, fluid mechanics, probability, statistics).

${ }^{18}$ Siegfried, Op. cit.: $75-76$.
} 
World University Rankings and its sister institute, EPFL 18th. Among these top universities, both ETH and EPFL are two of only three institutions located in a nonEnglish-speaking country. ${ }^{19}$

The technical education of company staff in Switzerland was complemented by a number of Universities of Applied Sciences which, given their practical orientation, were a strong source of technical talent for Swiss companies. Many of the firms in this research maintained close ties to such institutes, engaging frequently in joint projects. Many of the leaders of today's SMEs attended such institutions, sometimes prior to going on to graduate from ETH Zurich or EPFL Lausanne.

To summarize, Swiss science and engineering institutions have a long tradition of being connected to solving practical problems, supporting the innate drive of industry toward innovative solutions with practical applications.

\section{Tradition of Cooperative Governance}

Observers of political life in Switzerland have often commented about the special manner in which groups, parties, and communities interact with one another, greatly influencing the governance of Swiss enterprises.

Siegfried, writing about this phenomenon after his Swiss visit in 1950, described it as follows:

"The Swiss as a nation are the result of a balance of forces between a triple centrifugal cultural attraction and a triple centripetal political attraction. Three races, three, even four languages, and two religions, are associated in a political group which does not strive for ethnic, language, religious or cultural unity; yet, the result is an exceptionally united and an exceptionally national nation. How did this paradoxical result come about?"20

More recently, one of the authors, in private conversations with Stef Wertheimer, a leading Israeli entrepreneur with roots in Southern Germany, always returns to a similar question ${ }^{21}$ : "How come the Swiss have managed to overcome all these differences and build a such a strong export-oriented economy?"

Wertheimer, the founder of Iscar, a high-tech company producing tools for demanding metal cutting applications and which is active globally, was the creator of the Tefen Model. After stepping down from managing his company, Wertheimer spent much of his energy on creating German-style apprenticeship programs in Israel to foster some of the same educational effects he has observed in Switzerland. ${ }^{22}$

\footnotetext{
${ }^{19}$ QS Global University Rankings 2020. https://www.topuniversities.com/university-rankings/ world-university-rankings/2020. Accessed June 16, 2020.

${ }^{20}$ Siegfried, Op. cit.: 121 .

${ }^{21}$ Private conversations held by Jean-Pierre Jeannet with Stef Wertheimer, Israeli entrepreneur, on several occasions over the period of 2010 to 2018.

${ }^{22}$ Wertheimer, S (2015) The habit of labor. Overlook Duckworth, New York/London.
} 
Wertheimer is also a great admirer of the Swiss political system and its impact on the Swiss economy.

Two conversations with French executives who moved to Switzerland to manage and build companies help explain the differences and particularities of the Swiss political environment. The first conversation took place with a young entrepreneur who had crossed the border from France to work in Switzerland, working in both countries in the watch industry. When asked to reflect on the different experiences, he answered in a rather unexpected way.

"I moved from the French Jura, working for a French watch company, to the Swiss side, to the La Chaux-de-Fonds region to be specific, also working for a watch company. The difference that struck me most was what happened when we went for lunch. Here in Switzerland, everyone went to a nearby restaurant, sitting at long tables, all ranks, functions, hierarchies mixed, enjoying lunch together and engaging in conversation. My previous experience in France was radically different: everyone sat at separate tables, according to rank, social status and function."23

The company profile on Selectron details another example of how the governance tradition in Switzerland combines with leadership styles at SMEs. The protagonist at Selectron, Emmanuel Hannart, was parachuted in from the Paris head office of a large global company into heading this fledgling business during difficult times. As he negotiated with local governments, he became familiar with the Swiss political style of concordance, or democracy by consensus, versus democracy by dominance based on majority rule. Hannart believed that the Swiss, used to practicing concordance in many aspects of their lives, were able to overcome disagreements without imposing a solution on everyone. He applied this principle successfully when Selectron company was sold to a much larger German firm.

The deal with Knorr included a three year earn-out period that, if successfully delivered, determined as much as 20 percent of the acquisition price. Hannart and his team were able to convince Knorr to base this acquisition not on a merger basis but on the basis of concordance, or mutual agreement of governing issues, and with operating autonomy. ${ }^{24}$

That such a governance system influences the practice of management within many SMEs has deep roots in the cooperative structure of the Swiss society. This is also documented in the work of Elinor Ostrom, the Norwegian Nobel Prize winning economist who studied cooperative arrangements in many societies. ${ }^{25}$ Among her examples of Common-Pool Resource, or $\mathrm{CPR}^{26}$ units, were Swiss cooperative arrangements about the management of water used among mountain

\footnotetext{
${ }^{23}$ Conversation with Emmanuel Raffner, CEO, Lauener \& Cie SA, Boudry (NE).

${ }^{24}$ The term "concordance" was derived from German "Konkordanz" to describe the particular governance system used in Switzerland involving all major parties and striving for consensus rather than being overruled by a dominant party in a "Dominanz" system. This model had been adopted in Switzerland by many civic and business organizations as a governance model. Adapted from Selectron company profile.

${ }^{25}$ Ostrom, E.: Governing the commons. Cambridge University Press, Cambridge, UK (2015).

${ }^{26}$ Ibid., p. 30 .
} 
farmers in the Valais. "In Switzerland, individuals are responsible to others and to oneself. This makes a difference for an entrepreneur working in Switzerland compared to France." 27

\section{A Deeply Rooted Work Ethic}

While many international observers have often discussed the Swiss work ethic, two recent popular votes have probably added much to its reputation.

- In 2012, Swiss voters defeated an initiative to grant themselves an increase in mandatory vacation annually from four to six weeks with 66 percent of the voters voting No.

- In 2016, Swiss voters defeated an initiative to establish a guaranteed minimum income, with 77 percent voting $N o$.

Many observers of Swiss society have commented on the industriousness of its population. One of the early recorded commentaries was made by Jean-Jacques Rousseau (1712-1778), remembering his stay in the Jura mountains when he was about 20 years old; he remarked on the craft orientation of local farmers and their engagement in all kinds of cottage industries, later to become the base of the watch industry.

"They ... make countless artifacts with their hands and put to use their inventive genius which nature gave them. ... They ... invent and make all sorts of instruments of steel, wood and cardboard. ... They ... even make some watches. ... And, what seems unbelievable, each joins in himself all the various crafts into which watchmaking is subdivided and makes all his tools himself. ... They make syphons, magnets, spectacles, pumps, barometers and cameras obscura [sic]. Their tapestry [sic] consists of masses of instruments of every sort; you would take a farmer's living room for a mechanic's workshop and for a laboratory in experimental physics. All know how to sketch, paint and calculate a bit; ...". ${ }^{28}$

More than 200 years later, Rougemont, wrote about the Swiss and their work ethic. "Industry can rely on their taste for work (le goût du travail) as central for the Swiss, both the base for their social contacts and even more so for their own life. And in many death announcements, one can find the note 'Work was his life.",29

Siegfried confirmed Rougemont's assessment of the Swiss and their traditional work ethic, partly influenced by a scarcity of natural resources. "The absence of oil and coal, for beyond all doubt some good fairy waived her wand over the cradle

\footnotetext{
${ }^{27}$ Conversation with Emmanuel Raffner, CEO, Lauener \& Cie SA, Boudry (NE).

${ }^{28}$ Rousseau, JJ (1960) Politics and the arts (Letter to M. D'Alembert on the Theatre, written 1758). Cornell University Press, Ithaca, NY.

${ }^{29}$ de Rougemont, D Op. cit.
} 
declaring: And you shall have no coal. In this way, Switzerland was saved from the temptation of mass production and condemned to superiority." ${ }^{30}$

At the front of his book about Switzerland, Siegfried quoted a fable written by Jean de la Fontaine (1621-1695), a French poem entitled "The Farmer and his Children." ${ }^{31}$ In the fable that begins with "work hard, sweat all you can, riches is what counts the least," La Fontaine recounts the story of a rich farmer who, prior to his death, pleaded with his children not to sell their inheritance, as a treasure was hidden somewhere on the land, on a location unknown even to him. He encouraged his children to go and search for it by turning the earth over after the harvest. After his death, the sons turned over every corner of the land, without ever finding the treasure. The land, however, yielded more than ever before. In this way, the old farmer showed his family that work itself was the treasure and that wealth did not count.

The reputation of a strong work ethic is also supported by a number of more current government statistics. According to OECD, Swiss workers labor 42.5 hours per week in industry, putting in about 5 to 10 percent more hours annually in comparison to workers in competing European countries. ${ }^{32}$

The Swiss, however, enjoy higher wages than employees in most competing European countries. In his analysis, Rudolf Strahm pointed out that it was not pay per hour that mattered, but labor productivity instead. ${ }^{33}$ Based on data from the IMD World Competitive Yearbook from 2004 and 2007, Switzerland was listed as the sixth most expensive country in labor costs per hour, but fifth in productivity per hour. Netting the two generates a form of margin earned per man-hour, and, at 66 percent, it is higher for Switzerland than the neighboring, competing exporting countries of Germany or Austria, and in line with Korea. ${ }^{34}$

Where Switzerland surpasses competing countries is not so much in the net margin but in the actual monetary amount (gross profit) per hour worked, which is, on average, double that of competing countries. Combining the higher number of hours worked per year (about 10 percent) with the much higher productivity per hour explains why Swiss industry is able to compete globally from one of the countries with the highest cost base in the world. The experience of maxon confirms this observation. Despite the wage level differences, the Swiss operation was still competitive on the basis of profit per person, the key operating metric used at maxon. The indirect costs at the Swiss operation were about two-thirds, with one-third for direct production. ${ }^{35}$

\footnotetext{
${ }^{30}$ Siegfried, A (1950) Switzerland: A democratic way of life. Jonathan Cape, London.

${ }^{31}$ Ibid., p. 68.

${ }^{32}$ OECD: OECD. Stat, Average annual hours worked per worker (2019).

${ }^{33}$ Strahm, RH (2010) Warum wir so reich sind (Why we are so wealthy). Hep Verlag, Berne.

${ }^{34}$ Netting means taking the difference between value-added per man-hour minus cost per man-hour to arrive at a value for net contribution per man-hour.

${ }^{35}$ Adapted from maxon company profile.
} 


\section{Swiss Management Philosophy}

A few years ago, a group of executives from different countries were brought together at Babson College, in the USA, to discuss differences in management styles between the USA, Europe, India, and China. ${ }^{36}$

Speaking for the US management community was a former auto industry executive and private equity investor with a Wall Street background. He went on to explain how financial analysis was driving much of the management decisionsthe importance of both short-term views and profits, acquisition for company growth, and the role of the CEO as a person and individual leader.

The Indian executive talked about combining Western Ways and Eastern Productivity with an emphasis on spiritual aspects and human resources, while the Chinese business owner placed family values based on religious traditions such as Taoism, Buddhism, and Confucius, as well as personal relationships being in the forefront.

The European representative, CEO of a large Swiss biotech firm, was more direct in saying: "We could not function with so much emphasis on finance as European employees need more than that to motivate themselves, such as a social purpose."

This response shows clearly that the traditional European and even more so the Swiss management philosophy are distinctly different from a financially driven approach sometimes described as a Wall Street type.

The business environment in Switzerland has undergone considerable change over the past decades, with a more financially driven style finding its way into many, usually larger companies. Still, among smaller firms what is sometimes referred to as Swiss SME-type management remains prevalent. This philosophy, in many ways, shaped the management practices of the documented firms and, as described as the Swiss management style. The difference between the Swiss and Anglo-Saxon management styles was also found in research covering a number of countries. ${ }^{37}$

The experience of Victorinox, a Swiss business best known for its pocket knives, and a company that was part of our original long list of 100 firms for this book, is highly relevant to this discussion. Carl Elsener, CEO and representative of the founding family's fourth generation, was recently quoted in an interview.

"We think and plan in terms of generations, at the stock exchange the focus is on the next quarter and shareholder value - this is inconsistent with our philosophy. As an alternative to an IPO, our family created in the year 2000 a foundation holding 90 percent of the company shares." 38

\footnotetext{
${ }^{36}$ Babson College, Wellesley MA, USA, April 9, 2008, on the occasion of the Babson Academy of Distinguished Entrepreneurs: (Thomas Stallkamp, Babson Board of Trustees, Ernesto Bertarelli \{Switzerland\}, Sunil Bharti Mittal \{India\}, Lee Man Tat \{China\}).

${ }^{37}$ House, RJ, Dorfman, PW, Javidan, M, Hanges, PJ, de Luque, MFS (2014) Strategic leadership across cultures: the GLOBE study of CEO leadership behavior and effectiveness in 24 countries. SAGE Publications, London.

38“"Wir denken und planen in Generationen - nicht Börsenquartalen," interview with Carl Elsener, CEO of Victorinox, June 11, 2020 (Neue Zürcher Zeitung, International Edition).
} 


\section{Switzerland: Exception or Role Model?}

Several company profiles reveal that some of the founders of, and prime movers in, these SMEs hailed from abroad, finding fertile ground in Switzerland for their entrepreneurial endeavors. This was the case for Sefar (France), maxon (Germany), and Datamars (Italy); a number of the later movers, or owners, in other companies also came from neighboring countries, such as in the case of Fraisa (Germany) and Selectron (France).

It would have gone outside the scope of this project to investigate in greater detail the experience of SMEs in other countries. By chance, a story surfaced at the time that this text was being finalized. Although the example cited in this story comes from a publishing company in Italy, and not an export-oriented manufacturer, the history of Casa Editrice Hoepli in Milan serves as an anecdotal example, raising an intriguing question: To what extent do the practices of Swiss SMEs apply elsewhere, if attempted?

Johann Ulrich Höpli (1847-1935), a Swiss-born entrepreneur, trained as a bookseller in Zurich, emigrated to Milan in 1870 where he acquired a bookstore. Known as Ulrico Hoepli, he turned the bookstore into a successful publishing venture, Casa Editrice Hoepli. He remained childless and left the business to his nephews. ${ }^{39}$ One hundred and fifty years later, the business was still operating, owned, and managed by the founder's descendants. Barbara Hoepli, now the board chair, runs the company together with two brothers; they are part of the 5th generation. The company publishes about 300 new titles annually and maintains a publishing list of more than 2000 titles, focused in the areas of manuals, educational books, and languages. In a recent interview, Barbara Hoepli explained some of the principles that were at the core of the firm's success. ${ }^{40}$

- We are strongly engaged in niches, something that has always been our strength.

- One of our niches are languages, such as Russian for Italians, Italian for Chinese.

- In the segment of dictionaries, we are market leader.

- We are experts for books, books are our product, and we are selling nothing else.

- As good Swiss, we have no debts, pay our employees their monthly salaries, and earn sufficient funds to finance the necessary investments.

The comments made by Hoepli are strikingly similar to the principles and practices espoused by Swiss SMEs: privately owned, focused on a market niche and being financially self-sufficient are all principles followed by the SMEs described in this book. This story was deemed sufficiently intriguing to share with readers, encouraging the idea that the principle of Swiss SMEs can also be

\footnotetext{
${ }^{39}$ Jung, J, Hoepli, U (1977) Am literarischen Webstuhl. Neue Zürcher Zeitung, Zurich.

${ }^{40}$ Gallarotti E (February 1, 2020) Unser Produkt ist das Buch. Interview with Barbara Hoepli. Neue Zürcher Zeitung, Zurich.
} 
successfully applied in other countries; this in the hope of serving not just a Swiss public but a wider international audience as well.

\section{Reflections}

This chapter is written with the expectation that some thought might be given to the fact that, on one hand, the practices described in this book did not take place in a complete vacuum but, instead, were born in an environment that favors a given type of management thinking and, on the other hand, many companies in Switzerland have benefited from the Swiss ecosystem without ever achieving what is profiled in the book's company profiles and without reaching the lifespan of the companies documented. This confirms that success has not been automatic and that a large part of the success over the long run, in fact, needs to be credited to individual entrepreneurs, managers, or SME ownership.

The authors are keenly aware that similar companies in Germany and Austria, with related philosophies and orientation, operate successfully. This observation leads to the question, if such a Swiss SME Model existed, could it be duplicated elsewhere, outside of Switzerland? Or, alternatively, has the study simply discovered certain practices that can lead to long-lasting and successful firms elsewhere? To conclusively test this hypothesis was beyond the scope of this project. However, it is intriguing. We leave the readers to ponder the question.

Open Access This chapter is licensed under the terms of the Creative Commons Attribution 4.0 International License (http://creativecommons.org/licenses/by/4.0/), which permits use, sharing, adaptation, distribution and reproduction in any medium or format, as long as you give appropriate credit to the original author(s) and the source, provide a link to the Creative Commons license and indicate if changes were made.

The images or other third party material in this chapter are included in the chapter's Creative Commons license, unless indicated otherwise in a credit line to the material. If material is not included in the chapter's Creative Commons license and your intended use is not permitted by statutory regulation or exceeds the permitted use, you will need to obtain permission directly from the copyright holder.

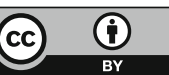

